natural configuration, until displaced by the new, tedioùslỳ-progressing formation.

CASE 2:-Mrsi: W—, an elderly female, applied to me, in $J$ une, on account of a swelling which had gradually appeared, ivithout evident cause, in the week previous, around the root of the nail on the second finger of the left hand. It had very much the character of a severe pinch, followed by extravasation of coagulum, excepting that it was hard, and attended with increasing uneasiness or pain. the whole finger was much swollen, and occasional throbbing extended from the part to the hand and arm. On freely dividing the swelling across with a scalpel, very little discharge followed, but what did escape was of an offensive, sanquinolent nature. After cauterizing the wound with nitrate of silver, I requested that a warm linseed poultice might be applied, thrice in 24 hours, with the arm in a sling. Each other morning for ten days I repeated the cauterization, which was only attended with the usual momentary suffering, when $I$ discovered with a probe the arch of the nail's root, and determined, as I had on previous occasions successfully done, to re move the irritating triangular portions of the nail, which always are buried deeply in the integument, even after the centre of the concavity is exposed. This was accomplished without difficulty, and my patient expressed her astonishment at the trifling pain it had occasioned. After their separation narrow adhesive straps were very tightly applied around the uleeration and the finger, (notwithstanding a considerable brown, mucous-like discharge at first oozed, and allowed to remain on four davs, at which time the wound had partly healed. A tight re-application of plaster was sufficient to effect the cure, and apparently the whole of the old nail remained, until naturally cast off by its successor, two months after the disease had disappeared.

\section{CURVATURE OF THE SPINE.}

\section{To the Editor of The Lancet.}

Sir:-I take the liberty, in consequence of the publication of the case treated by Dr. Harrison, in a late number of The LANCET, of addressing a few further lines to you respecting the treatment of lateral spinal distortion; I hope the ineficiency of the ordinary means parsued for the relief of that very distressing and prevalent complaint may be a sufficient apology for this step. The pathological views of this disease which I have ventured to adopt, are contained in The Lancex of the 15 th instant. They are, in a great measure, founded on the same opinions as those entertained by Dr. Harri- son, recognising a morbid extensibility of the ligaments, depending on general debilitt, and want of muscular tonicity. I do nnt, however, conceive that there is any actual sliding of the bodies of the vertebira upon each other, but merely an unnatural separa. tion, admitting of a degree of obliquity in their relative position. In the widest sense of the word, this may certainly be legarded as a dislocation of the vertebra. One of the main features in Dr. Harrison's plan of treatment is that of the replacement, or reduction, of this malposition, the beneficial effects of which, when it can be safely accomplished, must be evident to every educated practitioner. In order "to effect this object, Dr. H. makes use of extension, and suitable pressure, means being adopted, when the parts are restored to their uatual position, to retain them in situ, whilst the constitution is strengthened by the exlibjtion of appropriate remedies. The recumbent posture is, of course, enjoined, to preserve the parts in a proper state of tranquillity until the adjacent structures have regained their tone and infuence. But it appears to me, that in many cases of spinal distortion, the vertebræ must become much changed in figure, the undue pressure which they exercise on each other giving rise to absorption, in the same manner as that in which new sockets are formed for the heads of bones in cases of unreduced dislocations. This adaptation of bones to the pressiure of surrounding parts is, indeed, a perfectly healthy action, resulting from the natural process of absorption and deposition which is constantly going forward in the animal economy, - a wise provision of nature to relieve the inconvenience which would otherwise ensue. The same objections, therefore, appear to operate against the restoration of the distorted spine, which prevent our attempting the reduction of old dislocations, namely, that the parts originally suited for juxta-position no longer' correspond. I have seen vertebræ, the bodies of which presented an appearnice resembling the key-stone of an arch, the apex being on one side and the base on the other. Omitting the cases of scrofulous caries of the spine, and those of simple displacement, attended with a change is the configuration of the vertebræ, as being unfit for mechanical interference, what would be the proportion of cases in which it might be resorted to with safety? I have the honour to be, $\mathrm{Sir}$, your obedient servant,

J AMES BOWER HARRISON,

Manchester, Oct. 24,1836. 